\title{
Biomass, composition and size structure of invertebrate communities associated to different types of aquatic vegetation during summer in Lago di Candia (Italy)
}

\author{
Celine TESSIER, Antonia CATTANEO*, Bernadette PINEL-ALLOUL, Gaetano GALANTI ${ }^{1)}$ \\ and Giuseppe MORABITO ${ }^{1)}$ \\ Départ. de Sciences Biologiques, Université de Montréal, C.P. 6128, succursale Centre Ville, Montréal, Québec, Canada H3C 3J7 \\ ${ }^{1)}$ CNR Istituto per lo Studio degli Ecosistemi, Largo V. Tonolli 50, 28922 Verbania Pallanza, Italy \\ *e-mail corresponding author: antonia.cattaneo@umontreal.ca
}

\begin{abstract}
We compared the biomass, taxonomic composition, and size distribution of invertebrates associated to emergent (Schoenoplectus lacustris), submerged (Myriophyllum spicatum), and floating leaved (Trapa natans) vegetation at two depths (surface and water column) during summer in Lago di Candia, Italy. Invertebrate biomass was positively related to epiphyton biomass (Chl-a). M. spicatum supported higher invertebrate biomass per unit of plant weight than S. lacustris whereas T. natans was somewhat intermediate. Depth did not affect invertebrate biomass significatively. Surface sections of M. spicatum and T. natans supported invertebrate communities with similar taxonomic composition dominated by oligochaetes and ostracods. Large hirudineans and gastropods characterized the communities on the water column sections of $\mathrm{M}$. spicatum. S. lacustris and the water column sections of $\mathrm{T}$. natans (composed of stems and aquatic roots) were supporting invertebrate communities dominated by copepod nauplii and lacking large organisms. Changes in aquatic vegetation in Lago di Candia following harvesting of $\mathrm{T}$. natans and removal of submerged vegetation by the invasion of the rodent coypu (Miocastor coypus) may affect the invertebrate biomass of its littoral zone.
\end{abstract}

Key words: phytophilous invertebrates, epiphyton, Trapa natans, Schoenoplectus lacustris, Myriophyllum spicatum

\section{INTRODUCTION}

Aquatic vegetation in lake littoral zone represents a complex habitat, which offers support, protection and food to aquatic fauna. High invertebrate densities and biomasses are often associated to extensive and diversified aquatic vegetation (Crowder \& Cooper 1982; Gilinsky 1984; Diehl 1992).

Because of their differing architecture, aquatic plants can support invertebrate communities varying in biomass, size structure and taxonomic composition (Dvořak \& Best 1982; Cyr \& Downing 1988; Hanson 1990; Feldman 2001; Cheruvelil et al. 2002). Plants with dissected leaves may favour invertebrates by offering support and protection against predators. Furthermore, a dissected substratum may represent a better food source for invertebrates than morphologically simple plants because of its larger surface colonized by epiphyton. Plant architecture can also influence the phytophilous invertebrates by affecting light penetration and dissolved oxygen in the water column (Caraco \& Cole 2002).

Several fish species live among the littoral vegetation where they can reduce their risk of predation by piscivorous fish and feed on phytophilous invertebrates (Crowder \& Cooper 1982; Gilinsky 1984; Mittlebach 1988). Because littoral zone invertebrates play a key role in the energy transfer from primary producers to fish (Boisclair \& Leggett 1985) it is important to study their response to vegetation alterations.
During summer, three types of vegetation grow side by side in the littoral zone of Lago di Candia, a small lake in northern Italy: the emergent Schoenoplectus lacustris, the submerged Myriophyllum spicatum, and the floating-leaved Trapa natans (water chestnut). While S. lacustris is constituted of a unique stem, the architecture of $M$. spicatum is much more complex with secondary ramifications that increase the plant surface/mass ratio. T. natans morphology varies with depth. Leaf rosettes form a dense canopy at the water surface hindering light penetration. Underneath the canopy, in the water column, T. natans presents stems with much dissected aquatic roots.

The composition of the aquatic vegetation of Lago di Candia underwent important modifications during the past two decades. A selective harvest of T. natans was initiated in 1986 as part of a biomanipulation project to counteract eutrophication by reducing internal nutrient loading (Galanti et al. 1990). Following this harvest and in consequence of a marked increase in water transparency, submerged macrophytes, particularly Ceratophyllum demersum and Najas marina, colonized some space previously occupied by Trapa natans and expanded their presence to deeper sites (Giussani et al. 1997; Cattaneo et al. 1998). Submerged vegetation reached its maximum expansion in 1995 and then started to decrease dramatically in coincidence with the invasion of the lakeshore by the rodent Miocastor coypus (coypu) and, possibly, with the increase of grazing water fowls. At the time of our study, $C$. demer- 
sum and $N$. marina were absent whereas the cover of $M$. spicatum and $T$. natans was considerably reduced. On the contrary, emergent ( $S$. lacustris) and other floatingleaved plants (Nymphaea alba, Nymphoides peltata and Nuphar luteum) were not affected, probably because less palatable to this rodent and to water fowl.

If invertebrate communities colonizing different types of macrophytes vary in quantity and quality, previous and future changes in the littoral vegetation of Lago di Candia, may have important impacts on the lake littoral food webs. Thus, better assessment of changes in phytophilous invertebrate in response to variations in littoral vegetation is needed. This study aims to test if phytophilous invertebrates were affected by the architecture of the host plants co-occurring in Lago di Candia during summer in which macrophytes reach their highest biomass. To this end, we compared biomass, size structure and taxonomic composition of the invertebrate communities associated to emergent, submerged and floating-leaved plants. We also measured epiphyton biomass associated to these three types of vegetation because epiphyton is an important resource for phytophilous invertebrates and thus likely to explain a significant part of their variation.

\section{METHODS}

\subsection{Study site}

Lago di Candia is a small $\left(1.52 \mathrm{~km}^{2}\right)$ eutrophic lake of Northern Italy $\left(45^{\circ} 19^{\prime} \mathrm{N}, 7^{\circ} 54^{\prime} \mathrm{E}\right)$. The limnological characteristics of Lago di Candia vary very little spatially and are indicative of a lightly alkaline system, well mineralized and rich in nutrients (phosphorus and nitrogen) (Giussani et al. 1997 and Tab. 1). At sampling, we measured water physical and chemical characteristics near each vegetation type. Subsurface water samples were collected for laboratory measurements of $\mathrm{pH}$, conductivity (reference temperature $20{ }^{\circ} \mathrm{C}$ ), total nitrogen (TN; Valderrama 1981), total phosphorus (TP; Valderrama 1981), and phytoplankton chlorophyll a (Chl-a). Temperature was measured in situ with a temperature probe LAB90. Light extinction profiles were obtained by measuring light intensity between 400 and $700 \mathrm{~nm}$ (PAR radiation) at different depths using a LICOR LI-192 SB.

Tab. 1. Limnological characteristics of Lago di Candia. Chemical and biological variables were measured near the three types of vegetation on July $17^{\text {th }}, 2001$.

\begin{tabular}{lccc}
\hline Variable & S. lacustris & M. spicatum & T. natans \\
\hline Temperature $\left({ }^{\circ} \mathrm{C}\right)$ & 26.1 & 26.1 & 27.0 \\
$\mathrm{pH}$ & 7.58 & 7.83 & 7.78 \\
Conductivity $\left(\mu \mathrm{S} \mathrm{cm}^{-1}\right)$ & 113.9 & 113.9 & 114.2 \\
Total N $\left(\mathrm{mg} \mathrm{l}^{-1}\right)$ & 0.71 & 0.68 & 0.78 \\
Total P $\left(\mu \mathrm{g} \mathrm{l}^{-1}\right)$ & 32 & 32 & 44 \\
Phytoplankton Chl- $a\left(\mu \mathrm{g} \mathrm{l}^{-1}\right)$ & 11.8 & 11.3 & 11.7 \\
\hline
\end{tabular}

\subsection{Experimental design}

Sampling occurred on July $17^{\text {th }}$ and $18^{\text {th }}, 2001$, coinciding with the period of maximum plant biomass. $S$. lacustris and $M$. spicatum are perennials, while $T$. natans is an annual that germinates by seeds in late April and completely disappears in November (Galanti et al. 1990). The three types of vegetation were sampled in three pure stands that were located at a distance of about $40 \mathrm{~m}$ from each other. A previous study (Cattaneo et al. 1998) found that spatial differences in algal and invertebrate littoral communities are small around this lake. M. spicatum and T. natans were sampled near the surface (surface) and in the water column at an approximate depth of $1.5 \mathrm{~m}$ (deep). The emergent $S$. lacustris, present only in shallow water, could be sampled only near the surface. The depth comparison was particularly relevant for $T$. natans because its morphology near the surface, mainly composed of leaf rosettes, differs greatly from its morphology below the canopy characterized by stems and aquatic roots.

\subsection{Sampling of vegetation for epiphyton analyses}

Five sections (replicates) of plant, chosen haphazardly, were cut underwater with scissors and gently brought to the surface taking care not to disturb the biofilm on the plants. Epiphyton was separated from the plant by vigorously shaking the plant fragments for 1 min in a 2-1 plastic bottle containing 1.21 of tap water. A volume of the epiphyton suspension, varying between 25 and $70 \mathrm{ml}$, was filtered through Whatman GF/C glass fiber filters for Chl- $a$ determination. Chl- $a$ was analyzed by spectrophotometry after overnight extraction with 95\% ethanol in the dark. Chl- $a$ calculations were performed as in Bergman \& Peters (1980). The plants were dried at $105^{\circ} \mathrm{C}$ for $24 \mathrm{~h}$ in an oven for dry mass determination. Epiphyton biomass is expressed as Chl- $a$ per substratum dry weight ( $\mu \mathrm{g} \mathrm{g}^{-1} \mathrm{~d}$.w. vegetation).

\subsection{Sampling of vegetation for invertebrate analyses}

For each vegetation type and depth, a diver collected five replicate samples by closing a Plexiglas box (5.7 liters) around the vegetation (Downing \& Cyr 1985). This device allowed to sample quantitatively all invertebrates including those loosely associated with the vegetation. The entire content of the sampler was emptied in a 10-1 plastic container and vigorously agitated for $1 \mathrm{~min}$ to dislodge the invertebrates. The water was then filtered on a $63 \mu \mathrm{m}$ mesh sieve to retain invertebrates and plant fragments. The invertebrates were preserved in $70 \%$ ethanol for taxonomic analyses. The plants were dried in an oven at $105^{\circ} \mathrm{C}$ for $24 \mathrm{~h}$ for dry mass determination. 
Tab. 2. Light extinction profiles in the three macrophyte stands for July $17^{\text {th }}$ and $18^{\text {th }}, 2001$. $^{\text {a }}$ : Light underneath leaf canopy; ${ }^{\mathrm{b}}$ : Light outside macrophyte stand; *: \% of incident light was measured immediately below the surface of the water.

\begin{tabular}{|c|c|c|c|c|c|c|}
\hline \multirow[t]{2}{*}{ Depth (m) } & \multicolumn{3}{|c|}{ July $17^{\text {th }}, 2001$} & \multicolumn{3}{|c|}{ July $18^{\text {th }}, 2001$} \\
\hline & S. lacustris & M. spicatum & T. natans & S. lacustris & M. spicatum & T. natans \\
\hline Surface* & 0.773 & 0.649 & $0.127^{\mathrm{a}}$ & 0.174 & 0.675 & $0.614^{\mathrm{b}}$ \\
\hline 0.5 & 0.032 & 0.127 & 0.021 & 0.025 & 0.068 & 0.052 \\
\hline 1.0 & & 0.027 & 0.014 & & 0.020 & 0.014 \\
\hline
\end{tabular}

\subsection{Invertebrate taxonomic analyses and biomass determination}

In the laboratory, invertebrates were separated by sieving into two size fractions $(63-400 \mu \mathrm{m}$ and $>400$ $\mu \mathrm{m})$ to facilitate sorting. Invertebrates were counted, measured and identified to major groups or family under a binocular at 16,40 or $50 \times$ magnification. When invertebrate samples were very rich ( $>500$ individuals), we analyzed sub-samples. The size of these sub-samples was established so that at least 150 individuals of the most abundant taxonomic groups were counted. Individual dry weight was estimated from body length, using various length-weight equations from the literature (Eckblad 1971; Dumont et al. 1975; Mason 1977; Tudorancea et al. 1979; Smock 1980; Rosen 1981; Peters \& Downing 1984; Burgherr \& Meyer; 1997; Benke et al. 1999). Besides expressing invertebrate biomass per plant dry weight ( $\mathrm{mg} \mathrm{g}^{-1} \mathrm{~d}$.w.), we expressed it per water volume $\left(\mathrm{mg} \mathrm{l}^{-1}\right)$ to better compare among samples the invertebrates that are not directly attached to the vegetation.

\subsection{Statistical analyses}

One-way analyses of variance, followed by Tukey multiple comparison tests, were conducted to compare total invertebrate biomass and epiphyton Chl- $a$ among the three types of vegetation and the two depths (surface and water column). A simple regression analysis was performed to evaluate the relationship between epiphyton Chl- $a$ and total invertebrate biomass. Prior to analyses, invertebrate biomass and epiphyton Chl- $a$ were logtransformed to stabilize the variance. Statistical analyses were performed using the analytical software Statistix for Windows version 2.0 (Analytical Software, Tallahassee, Fl.).

To examine differences in invertebrate taxonomic composition among vegetation types and depth, we used ordinary principal components analysis with centering by species (CANOCO for Windows, version 4; ter Braak \& Šmilauer 1998). Prior to analysis, values of invertebrate biomass were transformed to Hellinger distances to make them usable in linear analyses as suggested in Legendre \& Gallagher (2001).

Invertebrates were grouped in logarithmically $\left(\log _{2}\right)$ increasing size classes to examine the size distribution of the communities.

\section{RESULTS}

\subsection{Physical and chemical characteristics}

Physical and chemical characteristics measured near the three types of vegetation were similar (Tab. 1) but light extinction varied (Tab. 2). Light penetration below the leaf rosettes of $T$. natans was lower than in free water among stands of $M$. spicatum or S. lacustris. This difference is likely related to the denser canopy formed by the thick floating leaves of T. natans. The low light penetration observed in stands of $S$. lacustris could be a consequence of shading by the emergent portion of this plant.

\subsection{Epiphyton and total invertebrate biomass}

Epiphyton biomass (as Chl- $a$ ) was significantly higher on $M$. spicatum than on $S$. lacustris and $T$. natans, which were not significantly different (Fig. 1). On $T$. natans, epiphyton Chl- $a$ was significantly higher on the stems and aquatic roots in the water column than on the floating leaves at the water surface. M. spicatum showed no significant depth variation in epiphyton Chl- $a$.

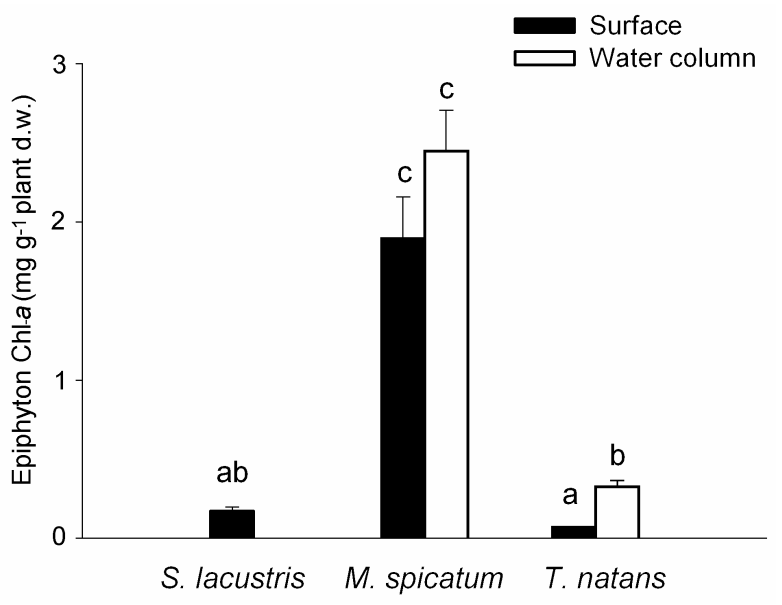

Fig. 1. Epiphyton Chl- $a$ associated to the three macrophytes, at the water surface and in the water column. Bars represent mean values $(n=5)$ with standard errors. Bars marked with different lower-case letters are significantly different from each other (ANOVA followed by Tukey multiple comparison tests, $\mathrm{p}<0.01)$.

In general, variation patterns in total invertebrate biomass ( $\mathrm{mg} \mathrm{g}^{-1}$ plant d.w.) agreed with those observed 

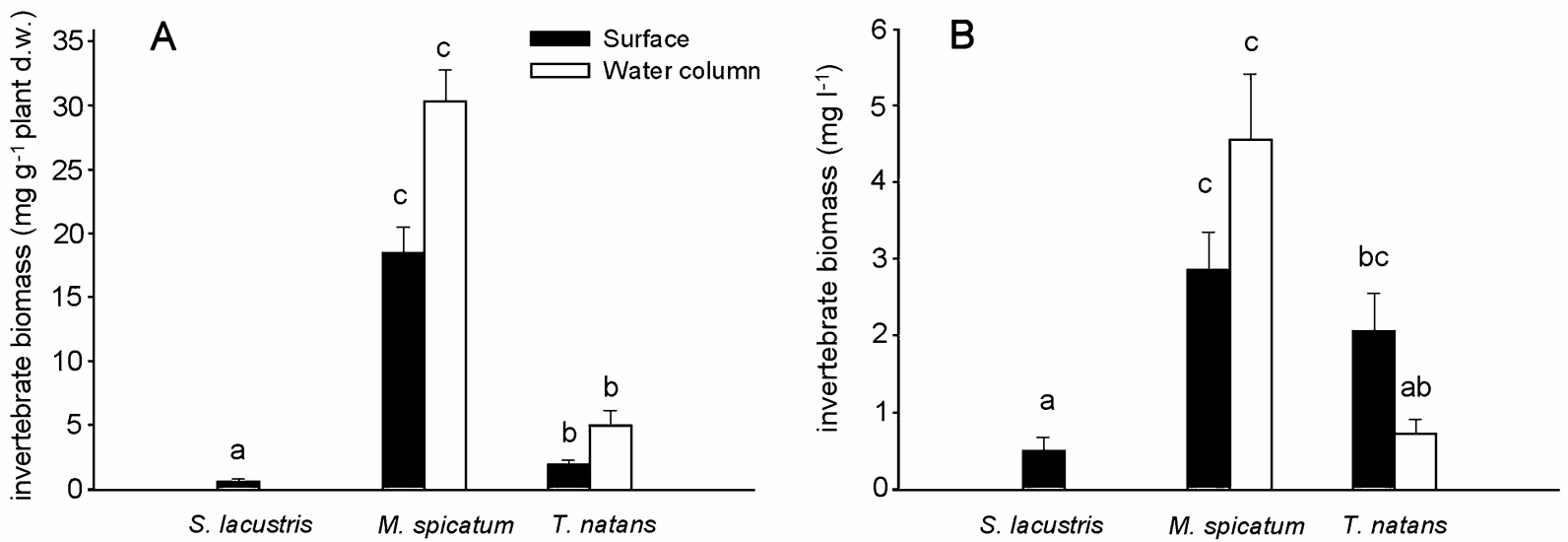

Fig. 2. Invertebrate biomass associated to the three macrophytes, at the water surface and in the water column. Values are expressed as $\mathrm{mg} \mathrm{g}^{-1}$ plant d.w. (panel A) and as $\mathrm{mg} \mathrm{l}^{-1}$ (panel B). Bars represent mean values $(\mathrm{n}=5)$ with standard errors. Bars marked with different lower-case letters are significantly different from each other (ANOVA followed by Tukey multiple comparison tests, $p<0.01$ ).

for epiphyton Chl-a (Fig. 2A). M. spicatum supported about 30 times more invertebrate biomass than $S$. lacustris. Biomass on T. natans was significantly higher than on $S$. lacustris but represented less than 1/7 of the biomass on M. spicatum. For both M. spicatum and T. natans, depth had no significant effect on total invertebrate biomass. When data were expressed per liter of water (Fig. 2B), the differences among vegetation were somewhat less striking but still significant. Highest biomass was on M. spicatum and lowest on S. lacustris. Biomass on $T$. natans was intermediate: values at the surface were not significantly lower than on $M$. spicatum and values in the water column were not significantly higher than on $S$. lacustris.

When all type of vegetation were considered, there was a close coupling between epiphyton Chl- $a$ and invertebrate biomass that were significantly positively correlated (Fig. 3A, equation 1). Inspection of the scatter plot suggested that invertebrate biomass observed on S. lacustris were lower than expected from this general relationship. An analysis of the residuals (ANOVA followed by Tukey multiple comparisons) of the regression between epiphyton and invertebrate biomass confirmed that residuals for $S$. lacustris were significantly different from residuals for the other plants (Fig. 3B). Omitting these outlier values, we recalculated the regression between epiphyton chlorophyll and invertebrate biomass (Fig. 3A, equation 2), which presented less scatter than the regression calculated using all data (Fig. 3A, equation 1).

\subsection{Invertebrate taxonomic composition}

Typical macrobenthic taxa like ostracods, annelids, gastropods, and several insect larvae, with the predominance of chironomids, were abundant in the phytophilous invertebrate communities. However, a significant portion of the biomass was represented by microcrustaceans, mostly copepods but also cladocerans, that are more loosely associated to the vegetation. The dominant invertebrate groups varied depending on macrophyte type and depth (Tab. 3). Copepod nauplii dominated the communities on S. lacustris (33\% of total biomass) and on T. natans-deep (31\%). Samples collected on M. spicatum-surface and T. natans-surface were dominated by Oligochaeta (34\% and 32\% respectively), whereas Hirudinea were prevalent $(34 \%)$ in $M$. spicatum-deep samples collected in the water column. A principal components analysis (PCA) showed that invertebrate samples could be differentiated on the basis of their composition (Fig. 4). The first axis of the PCA explaining $40 \%$ of the total variance separated the invertebrate samples collected on S. lacustris and on the stems and aquatic roots of $T$. natans (right size on Axis I) from all the others (left side on Axis I). These samples were characterized by high percentages of nauplii, Sididae, and chironomids. The second axis, which explained further $18 \%$ of the total variance in invertebrate assemblages, separated M. spicatum-deep samples characterized by high percentages of Hirudinea and Valvatidae gastropods from samples collected near the surface on $M$. spicatum and T. natans dominated by Oligochaeta, and Ostracoda. Some groups are restricted to few samples and separate them from the other replicates. It is the case of a sample of Trapa-surface characterized by high percentage of Odonata.

\subsection{Invertebrate size distribution}

Invertebrate biomass was differently partitioned among size classes depending on the vegetation type (Fig. 5). The smallest size classes $(<0.25 \mu \mathrm{g})$ were mainly represented by Rotatoria, which, although numerous, constituted $<2 \%$ of the total biomass everywhere. Invertebrates in the size class $0.5-1.0 \mu \mathrm{g}$ represented more than $30 \%$ of the total biomass of samples of $S$. lacustris and T. natans-deep. On the samples at the surface of $M$. spicatum and T. natans, the dominant size classes were 2-4 $\mu \mathrm{g}$ and 4-8 $\mu \mathrm{g}$ respectively, which represented close to $30 \%$ of the total biomass. 
A

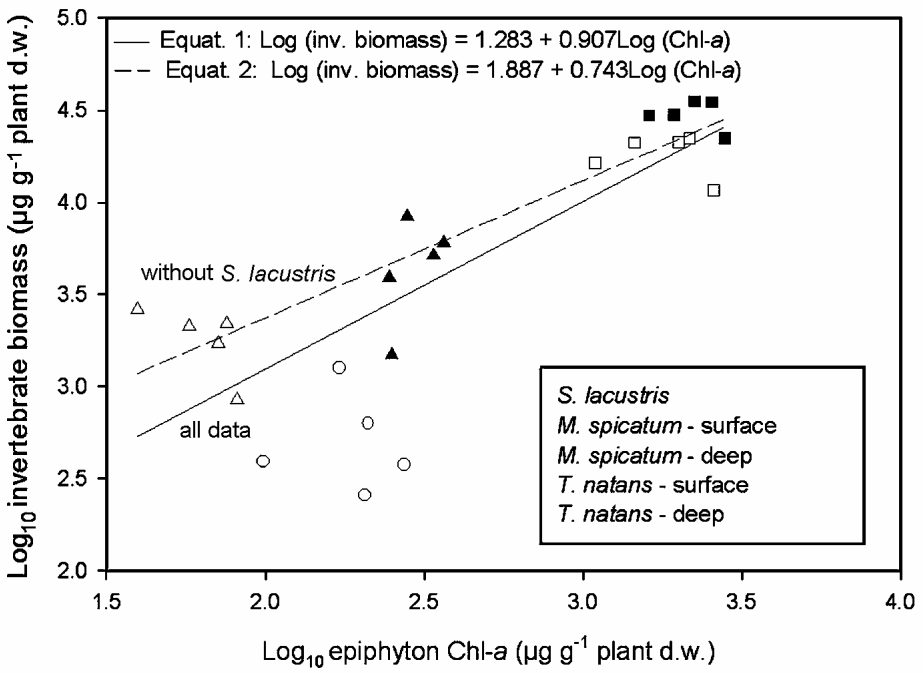

B

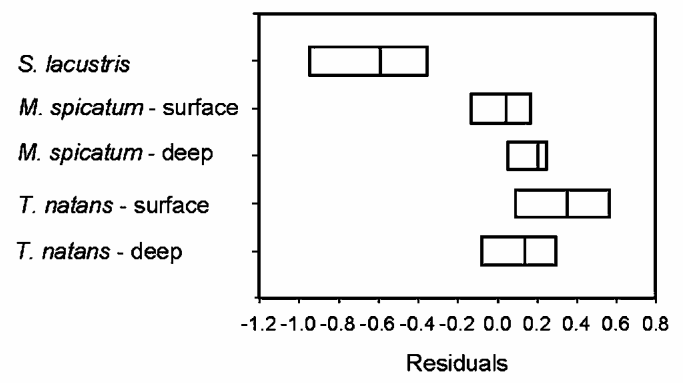

Fig. 3. A) Relation between epiphyton Chl- $a$ and total invertebrate biomass observed in the three types of vegetation. Regression calculated with all data is represented by the solid line (equation $1: n=25, r^{2}=0.64, F=42.9, p<0.0001$, residual variance $=0.17$ ). Broken line represents regression calculated excluding the samples collected on $S$. lacustris (equation 2: $n=20, r^{2}=0.83, F=0.96 .2$, $p<0.0001$, residual variance $=0.05$ ). B) Box plot of the residuals of above equation 1 observed for the different types of vegetation. The median value for each vegetation type is marked by the central vertical line; 25 and 75 -percentile values form the ends of the box.

Tab. 3. Percentage of the total invertebrate biomass represented by the taxa observed on three types of vegetation at different depths in Lago di Candia. Values represent the average, and standard errors are in brackets where $\mathrm{n}=5$. -: not present; + : percentage $<0.1$.

\begin{tabular}{|c|c|c|c|c|c|c|}
\hline \multirow[t]{2}{*}{ Taxon } & \multirow[t]{2}{*}{ Code } & \multirow[t]{2}{*}{ S. lacustris } & \multicolumn{2}{|c|}{ M. spicatum } & \multicolumn{2}{|c|}{ T. natans } \\
\hline & & & Surface & Deep & Surface & Deep \\
\hline Rotatoria & roti & $2.4(0.7)$ & $0.6(0.1)$ & $1.0(0.2)$ & $0.6(0.1)$ & $1.0(0.3)$ \\
\hline \multicolumn{7}{|l|}{ Copepoda } \\
\hline Calanoïda & cala & - & + & + & $0.1(0.1)$ & $2.9(1.2)$ \\
\hline Cyclopoïda & cycl & $1.9(0.2)$ & $4.5(0.7)$ & $3.2(0.7)$ & $1.6(0.4)$ & $4.4(0.8)$ \\
\hline Nauplii & naup & $32.9(13.5)$ & $2.5(0.8)$ & $1.9(0.3)$ & $2.6(1.5)$ & $30.8(8.5)$ \\
\hline \multicolumn{7}{|l|}{ Cladocera } \\
\hline Chydoridae & chyd & $1.7(0.5)$ & $2.3(0.2)$ & $0.9(0.2)$ & $2.9(0.6)$ & $1.9(0.5)$ \\
\hline Daphnidae & daph & - & $0.2(0.2)$ & + & + & $0.3(0.1)$ \\
\hline Sididae & sida & $3.1(1.4)$ & $1.2(0.4)$ & $0.7(0.5)$ & $3.2(1.5)$ & $5.6(1.7)$ \\
\hline Ostracoda & ostr & $9.7(3.0)$ & $26.2(3.1)$ & $14.3(3.0)$ & $21.1(4.5)$ & $10.7(3.5)$ \\
\hline Hydracarina & hydr & $4.6(4.0)$ & $2.6(1.2)$ & $2.9(1.0)$ & $0.6(0.4)$ & $2.1(0.9)$ \\
\hline \multicolumn{7}{|l|}{ Annelida } \\
\hline Hirudinea & hyru & - & $11.8(6.4)$ & $34.1(9.0)$ & $8.6(2.8)$ & $2.4(1.8)$ \\
\hline Oligochaeta & olig & $19.7(6.2)$ & $33.9(2.9)$ & $29.1(7.7)$ & $32.2(6.7)$ & $15.7(3.0)$ \\
\hline \multicolumn{7}{|l|}{ Gastropoda } \\
\hline Valvatidae & valv & - & $0.7(0.5)$ & $5.2(2.6)$ & $0.5(0.5)$ & - \\
\hline \multicolumn{7}{|l|}{ Diptera } \\
\hline Ceratopogonidae & cera & - & - & - & $7.2(2.4)$ & + \\
\hline Chironomidae & chir & $14.3(4.6)$ & $4.9(1.6)$ & $2.3(0.7)$ & $3.9(0.4)$ & $5.8(2.0)$ \\
\hline Ephemeroptera & ephe & + & - & - & + & $4.2(3.8)$ \\
\hline Hemiptera & hemi & $0.1(0.1)$ & - & - & $0.3(0.2)$ & - \\
\hline Odonata & odon & $0.2(0.1)$ & - & - & $12.3(8.8)$ & $1.9(1.2)$ \\
\hline Plecoptera & plec & - & $4.7(4.3)$ & $0.1(0.1)$ & $1.4(1.3)$ & $0.1(0.1)$ \\
\hline Trichoptera & tric & $8.8(5.0)$ & $3.9(1.5)$ & $4.0(3.3)$ & $0.9(0.3)$ & $10.3(3.2)$ \\
\hline Total biomass ( $\mathrm{mg} \mathrm{g}^{-1}$ plant d.w.) & & $0.58(0.18)$ & $18.48(1.98)$ & $30.35(2.38)$ & $1.90(0.30)$ & $4.98(1.14)$ \\
\hline Total biomass $\left(\mathrm{mg} \mathrm{l}^{-1}\right)$ & & $0.49(0.17)$ & $2.85(0.49)$ & $4.55(0.85)$ & $2.06(0.72)$ & $0.72(0.18)$ \\
\hline
\end{tabular}




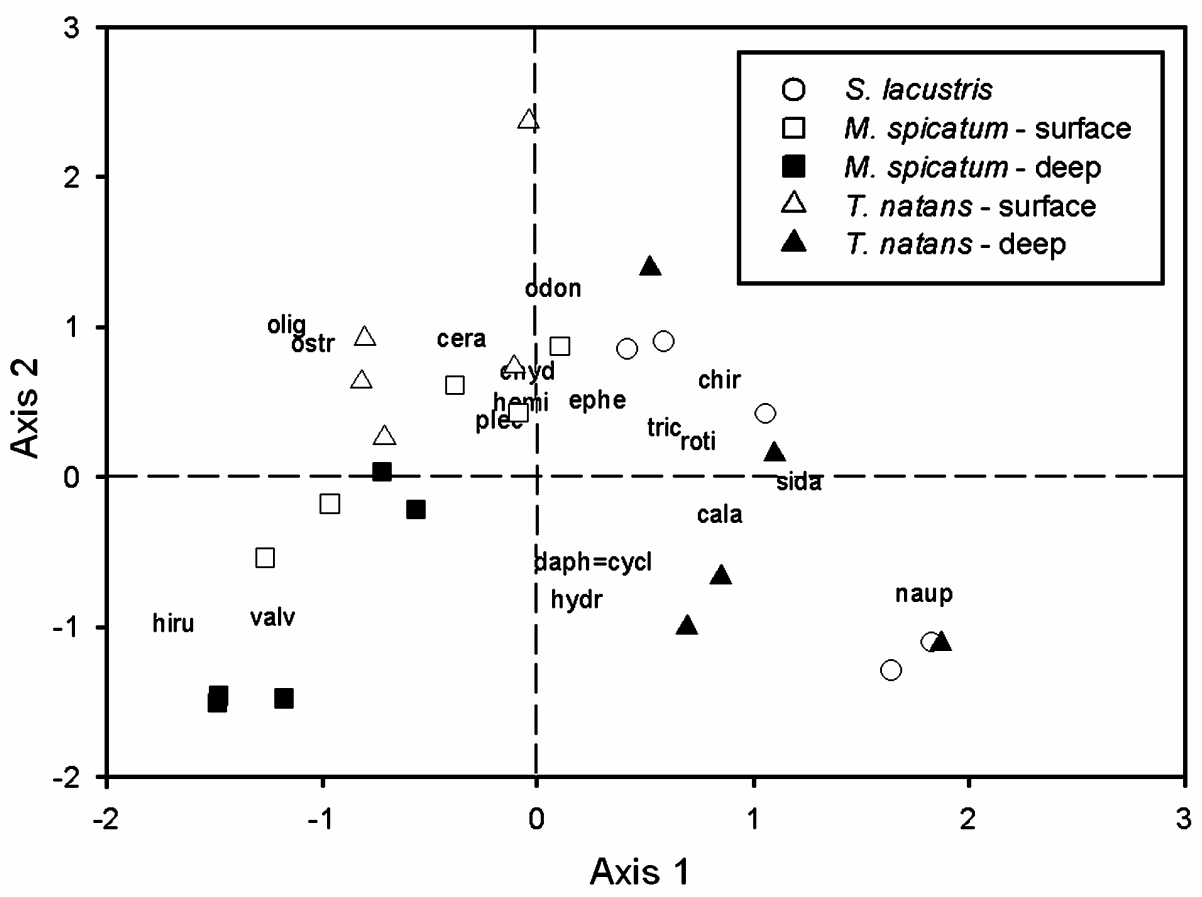

Fig. 4. Positions of samples and invertebrate taxa (codes as in table 3) along the first two axes defined by a principal components analysis.

On the M. spicatum-deep samples, there was a peak in percent biomass $(30 \%)$ corresponding to the size class $125-250 \mu \mathrm{g}$. Another major difference in the size structure among vegetation types was the absence of invertebrates in the largest size class $(>1 \mathrm{mg})$ in samples of S. lacustris and T. natans-deep. While the largest size class of invertebrates associated to $S$. lacustris was 125 $250 \mu \mathrm{g}$ (Hydracarina), surface samples on M. spicatum and $T$. natans supported invertebrates in size classes 2000-4000 $\mu \mathrm{g}$ (Plecoptera) and 8000-16000 $\mu \mathrm{g}$ (Odonata), respectively.

\section{DISCUSSION}

The three types of aquatic vegetation sampled in Lago di Candia had strongly different invertebrate biomass $\mathrm{g}^{-1}$ plant $\mathrm{d}$.w. These differences could partly arise from the fact that these plants vary in morphology and thickness and thus offer widely different amount of colonizable surface per unit of plant weight. The simple and thick stems of the emergent $S$. lacustris have a low surface/weight ratio of $\sim 70 \mathrm{~cm}^{2} \mathrm{~g}^{-1}$ plant d.w. (G. Galanti, unpublished data). In T. natans, surface/weight ratio is low for the leaf rosettes at the surface $\left(160 \mathrm{~cm}^{2}\right.$ $\mathrm{g}^{-1}$ ) but very high for stems and aquatic roots found in the water column $\left(1210 \mathrm{~cm}^{2} \mathrm{~g}^{-1}\right.$ ) (Galanti \& Romo 1997). Surface/weight ratios reported in the literature for $M$. spicatum range widely $\left(300-1200 \mathrm{~cm}^{2} \mathrm{~g}^{-1}\right) \mathrm{de}-$ pending on the amount of ramification and possibly on the methods (Cattaneo \& Kalff 1980; Sher-Kaul et al. 1995; Gosselain et al. 2004). These disparities in surface/weight ratios among plant types, although large, are not sufficient to offset the 30 -fold difference in in- vertebrate biomass observed between $M$. spicatum and S. lacustris. They could substantially decrease the 9-fold difference between $M$. spicatum and the surface rosettes of T. natans, however. Results of quantitative studies of vegetation distribution in aquatic systems are usually expressed as g plant d.w. $\mathrm{m}^{-2}$ (e.g. Chambers \& Kalff 1985; Duarte et al. 1986; Hudon 1997). Consequently, expression of invertebrate biomass per unit of plant d.w. facilitates estimates of areal biomass allowing an assessment of the impact of vegetation modifications on invertebrates.

Because several invertebrates are not directly attached to the substratum, it is meaningful to express invertebrate biomass also per unit of water volume. This alternative expression of the results keeps in account the three dimensional environment in which most aquatic organisms live, including fish. The pattern of highest biomass on $M$. spicatum, lowest on $S$. lacustris and intermediate on $T$. natans observed when expressing data $\mathrm{g}^{-1}$ plant d.w. persisted when data were expressed $\mathrm{l}^{-1}$. Our sampling method, which enclosed the plant as well as the surrounding water, and the use of a fine mesh $(0.63 \mu \mathrm{m})$ allowed including microcrustaceans and rotifers in our study. Meiofauna is not generally considered in studies of phytophilous communities, which address mostly the macroinvertebrates. Nauplii were the most important organisms in this meiofauna reaching similar biomass per unit of volume in all types of vegetation. However, their percentage contribution to total biomass varied from over $30 \%$ on $S$. lacustris to $2 \%$ on M. spicatum.

Taxonomic composition and size structure differentiated samples of $S$. lacustris and T. natans-deep from 


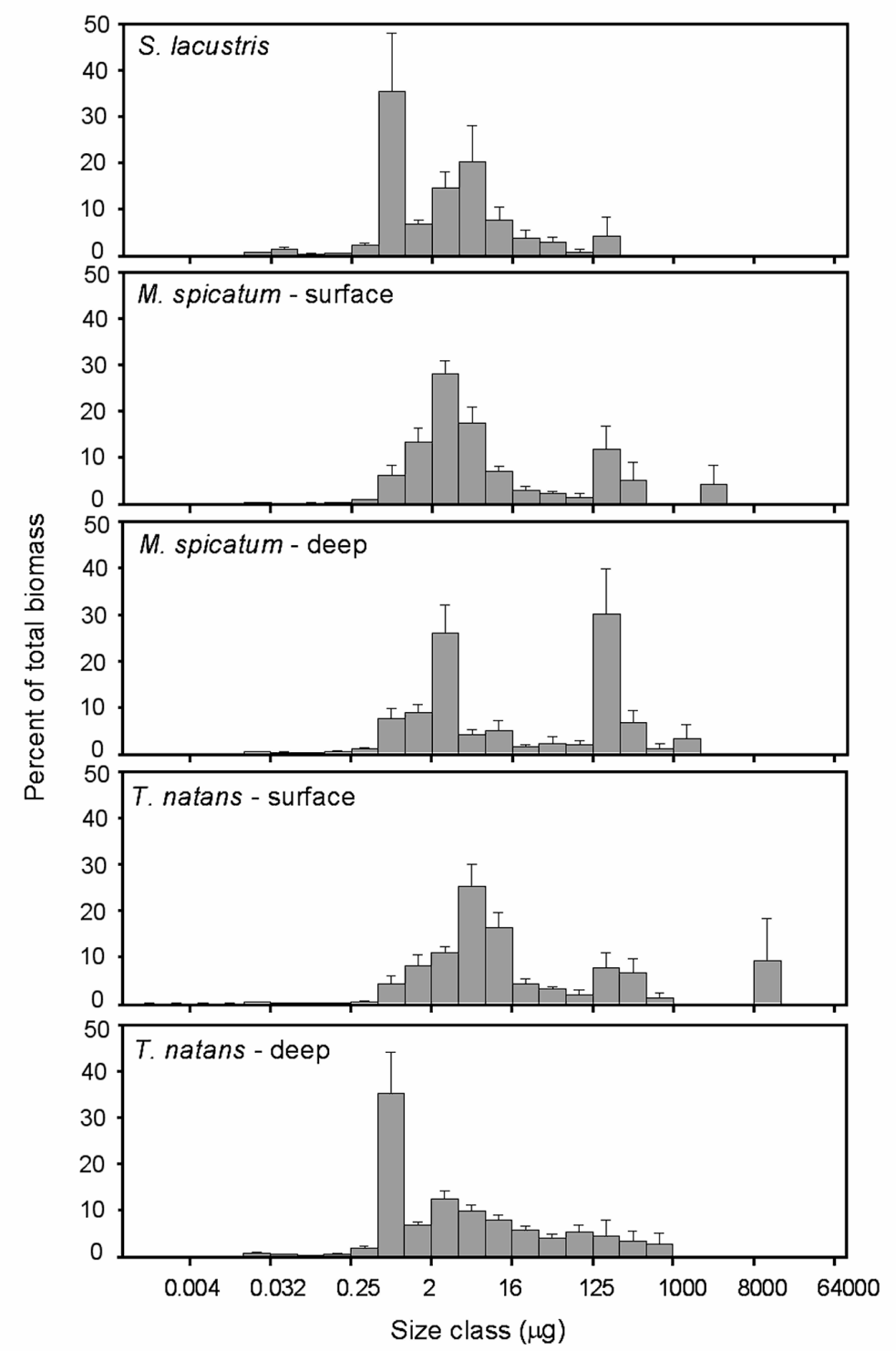

Fig. 5. Percent of total biomass observed in $\log _{2}$ size classes of individual d.w. on the three types of vegetation at the surface and in the water column. Bars represent mean values $(n=5)$ with standard errors.

all the others. Nauplii were the dominant group in these samples whereas the typical and larger benthic invertebrates were much reduced. This similarity is intriguing because the morphology of the simple stems of $S$. lacustris differs from the highly dissected aquatic roots observed in $T$. natans. Reduction of large invertebrates is usually considered as an indication of fish predation (Blumenshine et al. 2000). Indeed, on emergent macrophytes, lacking ramifications, leaves, and clumps, large invertebrates may not benefit of sufficient support and refuge against predation. This explanation for the scarcity of large invertebrates, however, applies less well to the relatively complex morphology of $T$. natans-deep. Furthermore, low light penetration under the surface canopy may represent a defense against visual predators like fish. This hypothesis was advanced to explain a slight shift towards large invertebrates observed on Trapa but not on Vallisneria in the Hudson River (Feldman 2001). Low light levels may limit epiphyton production in $T$. natans and therefore the resources to maintain large invertebrates. On the other hand, invertebrates were not likely to be resource limited on $S$. lacustris because invertebrate biomass was lower than expected from the epiphyton biomass. Different mechanisms, predation, and resource limitation, appear to lead invertebrate communities on S. lacustris and T. natansdeep towards similar taxonomic composition and size structure.

The effect of depth on the invertebrate communities differed depending on the vegetation. On M. spicatum, epiphyton and invertebrate biomass was higher, but not significantly, in the water column than near the surface. 
A similar vertical pattern in invertebrate density has been observed on submerged macrophytes in a Sweden lake (Marklund et al. 2001). Epiphyte and invertebrate biomass on $T$. natans was lower at the surface than in the water column when results were expressed per unit of plant d.w., but the opposite trend was found when biomass $1^{-1}$ was considered. This divergence is a consequence of the strikingly different vertical morphology of T. natans. The sampler included a much higher plant weight when closed around the thick leaf rosettes than when the thin stems and aquatic roots were collected. Similarly, in a previous work on epiphyton on T. natans in this lake (Galanti \& Romo 1997), epiphyton was highest on aquatic roots when expressed per unit plant weight but it was highest on leaf rosettes when expressed per unit of plant surface.

Samples collected near the water surface on $M$. spicatum and $T$. natans had similarities in invertebrate taxonomic composition and size structure. Ostracoda and Oligochaeta were dominant in both communities. Sections of M. spicatum-deep were instead characterized by the dominance of large Hirudinea as well as by a higher biomass of Valvatidae gastropods than in the other samples. Large invertebrates were more important at the surface on T. natans but in the water column on M. spicatum.

Gastropods and chironomids were the dominant macroinvertebrates on $T$. natans and on submerged plants in a previous study in this lake, which was also conducted in mid-summer (Cattaneo et al. 1998). The discrepancy in invertebrate taxonomic composition between the two studies may partly be explained by the different mesh size (300 versus $63 \mu \mathrm{m})$ altering the relative emphasis on large organisms. Nevertheless, we cannot exclude that the fauna may have changed in the 6-year lapse between the two studies, in which the lake has been perturbed by the invasion of the rodent coypu. Because sampling extended over only a few days in both studies, annual differences in invertebrate seasonal succession may have biased the comparison.

T. natans is a successful invader, which is able to displace the native submerged vegetation (Caraco \& Cole 2002). Invertebrate density on this invader was much lower than on nearby submerged vegetation in previous comparisons in the Hudson River (Feldman 2001) and in Lago di Candia (Cattaneo et al. 1998). Submerged plants harbored more invertebrate biomass per unit of plant d.w. than the emergent Typha both in a Dutch lake (Dvořak \& Best 1982) and in a fluvial lake of the St. Lawrence River (Tessier 2002). To our knowledge, this is the first study to compare invertebrate communities on $T$. natans to both submerged and emergent vegetation. Our results confirm that submerged vegetation is a superior host for invertebrates and suggest that $T$. natans is somewhat intermediate between submerged and emergent plants.
Changes in aquatic vegetation in Lago di Candia may affect the secondary production of its littoral zone. Typical standing crop of $S$. lacustris is $700 \mathrm{~g} \mathrm{~m}^{-2}$ (G. Galanti, unpublished data) whereas that of $T$. natans is $400 \mathrm{~g} \mathrm{~m}^{-2}$ (Galanti \& Romo 1997). These values together with our estimates of invertebrate biomass $\mathrm{g}^{-1}$ plant d.w. allow at least a rough estimate of the areal invertebrate biomass on different vegetation beds. According to these calculations, $T$. natans would harbour twice more areal biomass $\left(1062 \mathrm{mg} \mathrm{m}^{-2}\right)$ than $S$. lacustris $\left(420 \mathrm{mg} \mathrm{m}^{-2}\right)$. Even a small standing crop of M. spicatum $\left(50 \mathrm{~g} \mathrm{~m}^{-2}\right)$ could provide as much invertebrate biomass $\left(1200 \mathrm{mg} \mathrm{m}^{-2}\right.$ ) as a T. natans bed. Dense beds of M. spicatum $\left(>250 \mathrm{~g} \mathrm{~m}^{-2}\right)$ may reach an areal invertebrate biomass $\left(6000 \mathrm{mg} \mathrm{m}^{-2}\right)$ that is an order of magnitude higher than on $S$. lacustris. A previous study in Lago di Candia (Cattaneo et al. 1998) indicated that other submerged species, now completely absent, like $C$. demersum and $N$. marina are even better substrata than $M$. spicatum for epiphyton and macroinvertebrates. Therefore, the loss of submerged plants following coypu grazing may have seriously decreased the invertebrate production in the lake. On the other hand, an increase of submerged vegetation, promoted by mechanical harvesting of $T$. natans is auspicable. An increased development of emergent macrophytes and of $T$. natans, would scarcely affect the microcrustaceans living in loose association with the vegetation but would strongly reduce large invertebrates, which likely represent an important source of food for fish. Nevertheless, $S$. lacustris, by being present year round, can have an important ecological role providing substratum for phytophilous invertebrates over a more extended period than the other more seasonal plants.

\section{ACKNOWLEDGMENTS}

We thank Nicoletta Riccardi for her help in identifying the micro-invertebrates. Cinzia Orlandi assisted in the sampling and Andréanne Lauzé-Malouin in the sorting and measurement of the invertebrates. This study was supported by grants from NSERC and FCAR to A. C. and B. P.-A. It was also financed through a collaboration program between the governments of Québec and Italy (Coopération scientifique et technologique - Québec/ Italie 2000). C. T. thanks the Istituto per lo Studio degli Ecosistemi in Verbania for the warm hospitality during her stay in Italy.

\section{REFERENCES}

Benke, A.C., A.D. Huryn, L.A. Smock \& J.B. Wallace. 1999. Length-mass relationships for freshwater macroinvertebrates in North America with particular reference to the southeastern United States. J. North Am. Benthol. Soc., 18: 308-343.

Bergman, M. \& R.H. Peters. 1980. A simple reflectance method for the measurement of particulate pigment in lake water and its application to phosphorus-chlorophyll-seston relationships. Can. J. Fish. Aquat. Sci., 37: 111-114. 
Blumenshine, S.C., D.M. Lodge \& J.R. Hodgson. 2000. Gradient of fish predation alters body size distribution of lake benthos. Ecology, 81: 374-386.

Boisclair, D. \& W.C. Leggett. 1985. Rates of food exploitation by littoral fishes in a mesotrophic north-temperate lake. Can. J. Fish. Aquat. Sci., 42: 556-566.

Burgherr, P. \& E.I. Meyer. 1997. Regression analysis of linear body dimensions $v s$ dry mass in stream macroinvertebrates. Arch. Hydrobiol., 139: 101-112.

Caraco, N.F. \& J.J. Cole. 2002. Contrasting impacts of a native and alien macrophyte on dissolved oxygen in a large river. Ecol. Appl., 12: 1496-1509.

Cattaneo, A. \& J. Kalff. 1980. The relative contribution of aquatic macrophytes and their epiphytes to the production of macrophyte beds. Limnol. Oceanogr., 25: 280-289.

Cattaneo, A., G. Galanti, S. Gentinetta \& S. Romo. 1998. Epiphytic algae and macroinvertebrates on submerged and floating-leaved macrophytes in an Italian lake. Freshwat. Biol., 39: 725-740.

Chambers, P.A. \& J. Kalff. 1985. Depth distribution and biomass of submersed aquatic macrophyte communities in relation to Secchi depth. Can. J. Fish. Aquat. Sci., 42: 701709.

Cheruvelil, K.S., P.A. Soranno, J.D. Madsen \& M.J. Roberson. 2002. Plant architecture and epiphytic macroinvertebrate communities: the role of an exotic dissected macrophyte. J. North Am. Benthol. Soc., 21: 261-277.

Crowder, L.B. \& W.E. Cooper. 1982. Habitat structural complexity and the interaction between bluegills and their prey. Ecology, 63: 1802-1813.

Cyr, H. \& J.A. Downing. 1988. The abundance of phytophilous invertebrates on different species of submerged macrophytes. Freshwat. Biol., 20: 365-374.

Diehl, S. 1992. Fish predation and benthic community structure: the role of omnivory and habitat complexity. Ecology, 73: 1646-1661.

Downing, J.A. \& H. Cyr. 1985. Quantitative estimation of epiphytic invertebrate populations. Can. J. Fish. Aquat. Sci., 42: 1570-1579.

Duarte, C.M., J. Kalff \& R.H. Peters. 1986. Patterns in biomass and cover of aquatic macrophytes in lakes. Can. J. Fish. Aquat. Sci., 43: 1900-1908.

Dumont, H., I. Van de Velde \& S. Dumont. 1975. The dry weight estimate of biomass in a selection of Cladocera, Copepoda, and Rotifera from the plankton, periphyton, and benthos of continental waters. Oecologia, 19: 75-97.

Dvořak, J. \& E.P.H Best. 1982. Macro-invertebrate communities associated with the macrophytes of Lake Vechten: structural and functional relationships. Hydrobiologia, 95: $115-126$.

Eckblad, J.W. 1971. Weight-length regression models for three aquatic gastropod populations. American Midland Naturalist, 85: 271-274

Feldman, R.S. 2001. Taxonomic and size structures of phytophilous macroinvertebrate communities in Vallisneria and Trapa beds of the Hudson River, New York. Hydrobiologia, 452: 233-245.

Galanti, G. \& S. Romo. 1997. Epiphyton biomass on the floating leaved water chestnut (Trapa natans) and its importance for the carbon balance in the eutrophic Lake Candia (Northern Italy). Mem. Ist. ital. Idrobiol., 56: 95111.

Received: March 2004

Accepted: August 2004
Galanti, G., P. Guilizzoni \& V. Libera. 1990. Biomanipulation of Lago di Candia (northern Italy): a three-year experience of aquatic macrophyte management. Hydrobiologia, 200/201: 409-417.

Gilinsky, E. 1984. The role of fish predation and spatial heterogeneity in determining benthic community structure. Ecology, 65: 455-468.

Giussani, G., R. Bettinetti, G. Galanti, S. Gentinetta, P. Guilizzoni, A. Lami, R. Lo Bianco, \& A. Pugnetti. 1997. Studio sull'evoluzione delle condizioni ambientali del Lago di Candia conseguenti alle operazioni di gestione del popolamento ittico e della vegetazione acquatica. Report CNR-III, 01.97: $81 \mathrm{pp.}$

Gosselain, V., C. Hudon, A. Cattaneo, P. Gagnon, D. Planas, R. Léonard, \& D. Rochefort. (2004). Physical variables driving epiphytic algal biomass in a dense macrophyte bed of the St. Lawrence River (Québec, Canada): submitted.

Hanson, J.M. 1990. Macroinvertebrate size-distributions of two contrasting freshwater macrophyte communities. Freshwat. Biol., 24: 481-491.

Hudon, C. 1997. Impact of water level fluctuations on St. Lawrence River aquatic vegetation. Can. J. Fish. Aquat. Sci., 54: 2853-2865.

Legendre, P. \& E.D. Gallagher. 2001. Ecologically meaningful transformations for ordination of species data. Oecologia, 129: 271-280.

Marklund, O., I. Blindow \& A. Hargeby. 2001. Distribution and diel migration of macroinvertebrates within dense submerged vegetation. Freshwat. Biol., 46: 913-924.

Mason, C.F. 1977. Populations and production of benthic animals in two contrasting shallow lakes in Norfolk. $J$. animal Ecol., 46: 147-172.

Mittlebach, G.G. 1988. Competition among refuging sunfishes and effects of fish density on littoral zone invertebrates. Ecology, 69: 614-623.

Peters, R.H. \& J.A. Downing. 1984. Empirical analysis of zooplankton filtering and feeding rates. Limnol. Oceanogr., 29: 763-784.

Rosen, R.A. 1981. Length - dry weight relationships of some freshwater zooplankton. J. Freshwat. Ecol., 1: 225-229.

Sher-Kaul, S., B. Oertli, E. Castella, \& J.-B. Lachavanne. 1995. Relationship between biomass and surface area of six submerged aquatic plant species. Aquat. Bot., 51: 147154.

Smock, L.A. 1980. Relationships between body size and biomass of aquatic insects. Freshwat. Biol., 10: 375-383.

ter Braak, C.J.F. \& P. Smilauer. 1998. CANOCO reference manual and user's guide to Canoco for Windows: Software for Canonical Community Ordination (version 4). Microcomputer Power, Ithaca, USA.

Tessier, C. 2002. Influence de la structure des habitats végétaux sur les communautés d'invertébrés lacustres. Chapitre 1: Invertebrate communities associated to different types of aquatic vegetation with contrasting architecture. Masters Thesis, Département de sciences biologiques, Université de Montréal, Québec, Canada.

Tudorancea, C., R.H. Green \& J. Huebner. 1979. Structure, dynamics and production of the benthic fauna in Lake Manitoba. Hydrobiologia, 64: 59-95.

Valderrama, J. C. 1981. The simultaneous analysis of total nitrogen and total phosphorus in natural waters. Mar. Chem. 10: 109-122. 